\title{
PERFORMANCE EVALUATION OF ROOF-TOP PV SYSTEMS IN THE AREA OF KAVALA NORTH GREECE
}

\author{
Jacob Fantidis* \\ Technological Education Institute of Eastern Macedonia and Thrace, Kavala, Greece \\ Potolias Constantinos \\ Technological Education Institute of Eastern Macedonia and Thrace, Kavala, Greece \\ Demetrios Bandekas \\ Technological Education Institute of Eastern Macedonia and Thrace, Kavala, Greece \\ Panagiotis Kogias \\ Technological Education Institute of Eastern Macedonia and Thrace, Kavala, Greece \\ Efthymios Stathakis \\ Technological Education Institute of Eastern Macedonia and Thrace, Kavala, Greece \\ Konstantinos Karakoulidis \\ Technological Education Institute of Eastern Macedonia and Thrace, Kavala, Greece \\ K. Meresentoglou \\ Technological Education Institute of Eastern Macedonia and Thrace, Kavala, Greece
}

The continuously growing demand for electricity and the need to develop Renewable Energy Sources (RES), pushed the modern world to develop Photovoltaic (PV) systems. An evaluation of performance of photovoltaic power systems was conducted, aiming to analyze the causes of performance reduction of the systems. During the years 2010 - 2013 was a period which was described as «fever of photovoltaic» systems installation in Greece. There were so blatant manufacturing defects mainly to the roof-top PV systems. Studding their location and construction method, radically different, even in neighboring systems we find that the reflection on the performance conditions are reasonable and easy to understand. This is the reason that leads us to make a research study regarding the performance differences of the roof-top PV systems and the causes of them. Mainly we deal more with the systems of low performance $\leq 10 \mathrm{~kW}$, because they are more economical and interesting. In this paper, a study for the area of prefecture of Kavala, Greece is analyzed.

Key words: PV Systems, Roof, Greece, Evaluation

\section{INTRODUCTION}

Today, energy demand is one of the biggest problems worldwide, with enormous implications for the environment, economy and development. The exploitation of Renewable Energy Sources in the last few years aims not only towards less dependence on oil, but also protection of the environment [10, 02, 03].

In Greece the PV systems in the past decades, found little scope for action in marine applications such as lighthouses, floating buoys, etc. But in terrestrial remote and inaccessible from the grid areas, where the need for electric power was minimal or subsidiary, as the phone signal repeaters, charging of accumulators etc., PV systems could be used. The excessive cost of equipment, installation, and capture enough usable space was the main prohibitive factor for the development of the PV systems.

The growing demand for electric power and the need to develop RES pushed European governments including the Greek development programs to exploit PV systems [01]. During 2009, Greece in the Joint Ministerial Decision [08], prepared the special development program of rooftop PV systems in buildings up to $10 \mathrm{~kW}$, published in Government Gazette 1079/04.06.2009, to be effective from 01.07.2009 until 31.12.2019. In essence, the program is aimed for photovol- 
taic systems for generating electricity by the inverters which are installed on the roof of the buildings, including roofs and terraces. These systems will be installed one for each building and in no case will exceed $10 \mathrm{~kW}$. The system owner makes a contract stating that the electricity fed into the grid will be offset by the accounting Public Power Corporation S.A Hellas, (PPC) cost energy consumed for the purpose of building that hosted photovoltaics. This contract duration is 25 years. Here will be mentioned that the first roof-top PV system of that special program linked to the grid, is placed at Elefthere, in the area of Kavala Prefecture, on 2.10.2009 with nominal power 9,84 kW [08]. Manufacturing defects, installation errors, miscalculations of essential parameters of the systems and consequently, the reduce of the performance of these systems are integrated in our study. To perform our study we used for recorded measurements of electric energy attributed to the grid,(operator) [04], those systems that were connected to the grid from September 2010 to May 2012, which is the first 512 of the total 990 systems, of this special program for roof-top PV systems installed in the area of the prefecture of Kavala.

\section{METHODOLOGICAL FRAMEWORK}

Our study intends to identify the causes leading to reduced performance of roof top PV systems and identify the impacts of this problem. For Organize and process the numeric data we develop a computer program in Excel spreadsheets software.

\section{The input data}

Initially, the input data for a number of selected systems is:
a) The connection date of the system to the grid
b) The date of the last measurement of energy attributed to the grid of the Hellenic Electricity Transmission System, ADMIE [11]
c) The value of the last measurement of energy attributed to the grid in $\mathrm{kWh}$
d) The installed capacity of the system in kWp.

This procedure is addressed to give the initial elements to map out strategies for the best RES exploitation in a region, which fits demand and supply according to the many constraints and factors.

\section{The Output data}

Final output data for the certain systems include:

a) The Sum of production time (working days of the system)

b) The daily Total PV energy production (kWh)

c) The daily energy production $(\mathrm{kWh}) / \mathrm{sum}$ of installed capacity of PV system ( $\mathrm{kWp}$ ) under consideration

d) Configure the average of performance of the selected systems

e) Calculate the percentage of deviation for each system from the average of the selected systems

f) Finally, calculates the percentage of deviation of each system separately from the average of the ten most efficient systems registered

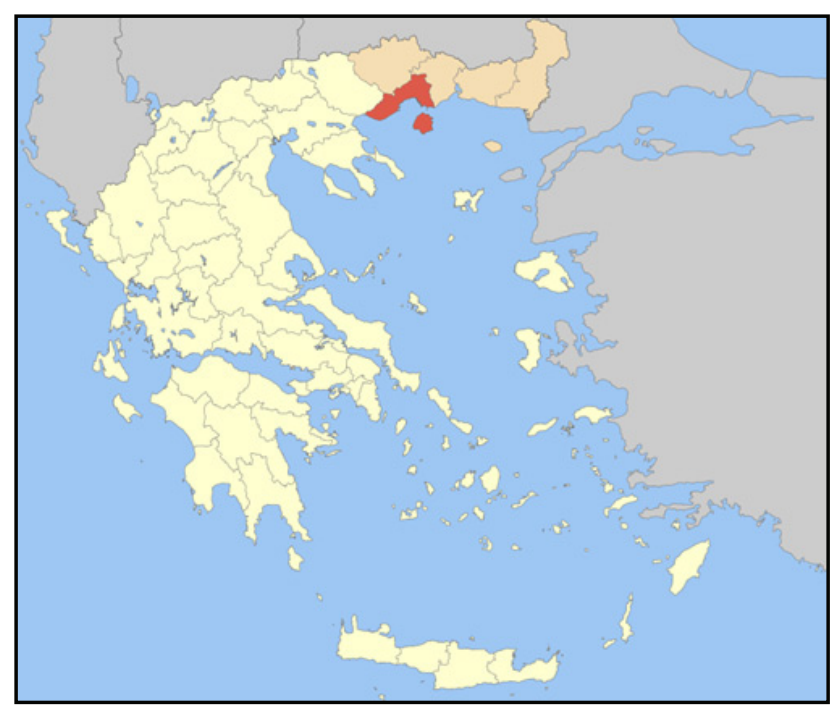

Figure1: Greece map, Kavala area

As well we try to compare the results with actual yield from many operational roof-top PV systems on REAL performances, after two years effective operating time. These plants are located in different climatic regions. We use these comparisons and experiences to further improve accuracy of our proposed model. We use full time series data and not typical data in our calculations.

\section{CASE STUDY}

The study takes place in the area of prefecture of Kavala (Figure 1). Kavala is a city in northern Greece, the principal seaport of eastern Macedonia and the capital of Kavala regional unit. It is situated on the Bay of Kavala, across from the island of Thasos. The Prefecture of Kavala is situated between two rivers, Strymonas and Nestos, 
which are a source of life for the area, while they stand out for their biodiversity and natural beauty (Figure 2). The population is 147.687 residents (2011) [06].
To perform the study we used for measurement the electric energy assigned to the grid [01], rather than random $\mathrm{PV}$ systems.

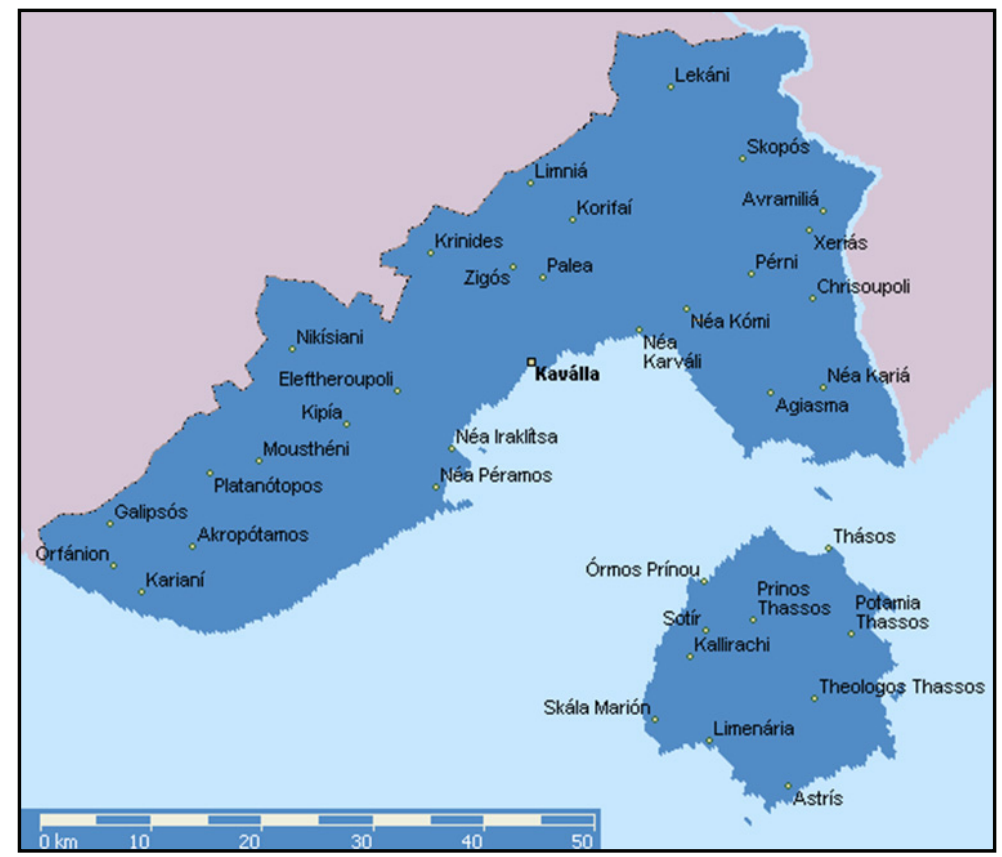

Figure 2: Area of Kavala prefecture

As mentioned, for the implementation of the proposed evaluation framework, data was based on the measurements data from systems that were connected from September 2010 to May 2012, which is the first 512 of the total, till today, 990 systems, of this program (roof-top PV systems) in prefecture of Kavala area.

Initially in these roof-top PV systems was no differentiation about the installed position (roof, terrace, etc.) or the location (city of Kavala, villages), position altitude, areas of Chrisoupoli, Elefteroupoli, Thassos (Figure 2). Since the last measurements of power produced from the PV systems were taken at the end of 2013 and the first months of 2014 , each system completes almost two years of production, including for each, two summer periods considered more efficient than winter. So we get to clearly draw conclusions about the performance of each system separately.

\section{RESULTS AND DISCUSSION}

Following the recording data, as first step we found:

The Average of the daily energy yield ( $\mathrm{kWh}$ )/sum of installed capacity of PV system (kWp) under consideration (512 roof-top PV systems).

\section{3,60 kWh/kWp}

It is the factor that can be used by experts for specific performance calculation of future systems in the nearby area. (Since the new program development PV systems "Net metering" is just around the corner) [07].

It is a factor that can be used as a comparator for each producer according to the performance of its own system.

Then as second step we choose ten systems with the maximum average rate of daily yield which is:

\section{$4,35 \mathrm{kWh} / \mathrm{kWp}$}

It is the optimal factor that should be targeted for future investment in the region and aims to improve the existing. We reach that conclusion because during processing, the results varied widely among the most efficient $(4,82 \mathrm{kWh} / \mathrm{kWp})$ and inefficient $(1,4 \mathrm{kWh} / \mathrm{kWp})$. Therefore the aforesaid discussion is realistic.

So we believe, the systems that cannot exceed $3 / 4$ of energy production of the optimal factor, or $84 \%$ of the average of the daily energy yield ( $\mathrm{kWh}$ /sum of installed capacity of PV system in $\mathrm{kWp}$ ), have design and construction defects, leading to generate low yields and require further investigation. 


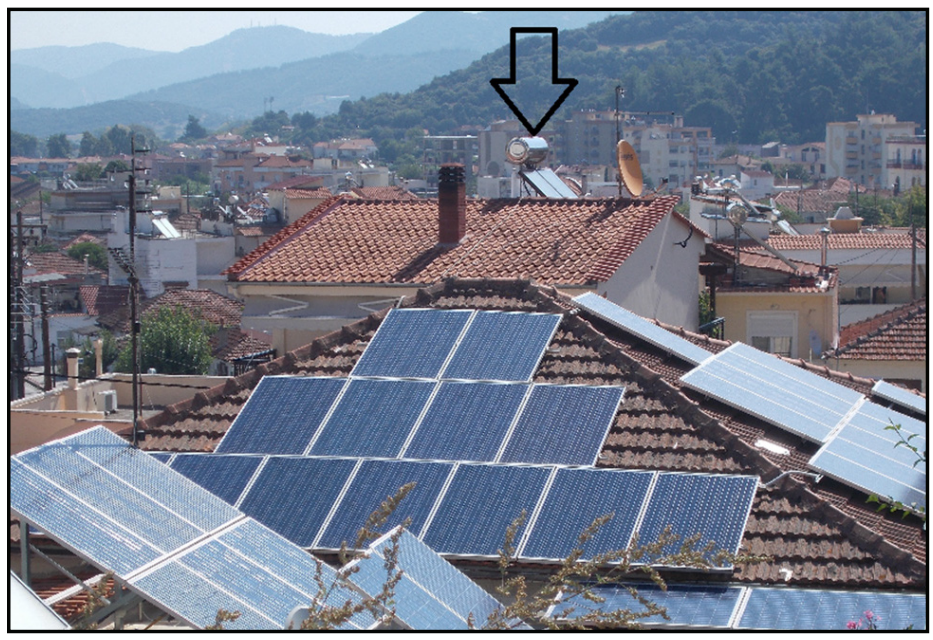

Figure 3: Wrong Orientation of roof-top PV systems

\section{Classifying causes of poor performance}

Our investigation, except the long time recorded measurements, for the justification of reduced performance systems, occurred in 70 worst of the 512 under consideration systems by the method of site visit. The observation started from the panels, specifically to, the location, orientation, wiring to dc inverter, the $A / C$ devices, even with information from the owners in order to find the causes of the low system performance.

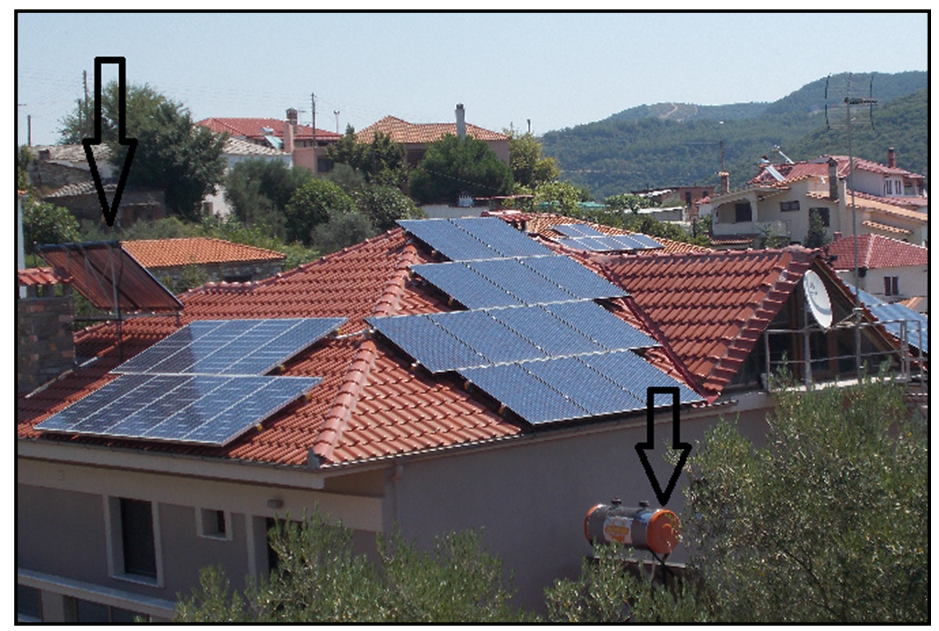

Figure 4: Wrong orientation PV panels

We believe that large part of the problems of rather $50 \%$ of the roof-top PV systems in Kavala area is found after this study and is classified in categories as listed below.

\section{PV Orientation problems}

We observed that in many PV systems, a significant part of the panels were placed in diametrically opposite position to the southern efficient position; at north, northeast, northwest, etc. (Figure 3).

This occurs mainly on the roofs, where the panels follow the path of the roof with a unique criterion to cover as many as possible available surface of the roof, also with aim of bringing the legal limit of $10 \mathrm{~kW}$. So we have in this case extra installed and inefficient capacity, regardless of inclination and orientation. Specifically in this case (Fig. 4) we notice the "anarchic» orientation, while the solar panel reveals the correct orientation. This system has an efficiency of $78 \%$ average. In this system (Figure 4), there are 9 panels on the back side of the roof, also the solar panel shows the south direction, and the system's performance in this case is $74 \%$ of average. Similar situation is in Fig 5., with the panels oriented in east - west direction with energy yield $80 \%$ of average quantity. In some plate roofs, the manufacturer chooses to follow panels parallelogram layout of the roof, sacrificing part of the optimal inclination and orientation. In this category are classified systems where the manufacturer has 
chosen to place the panel in horizontal position (Figure 6), expecting higher energy production at midday when the solar radiation is vertical, thereby offsetting the loss of the morning and afternoon hours of the day $[03,05]$.

\section{PV Shading problems}

Partially shaded photovoltaic modules typically exhibit additional difficulties [09]. Shadings are usu- ally created during the morning and afternoon, stronger in the winter months, when the sun is lower in the horizon fields. During our investigation, however, we observed that there are cases where shadings most of the time the blot sunshine. These came from residential smokestacks, building barriers, adjacent trees, adjacent buildings, also by the overlap between the panels, even by natural barriers such as mountains (Figure 7).

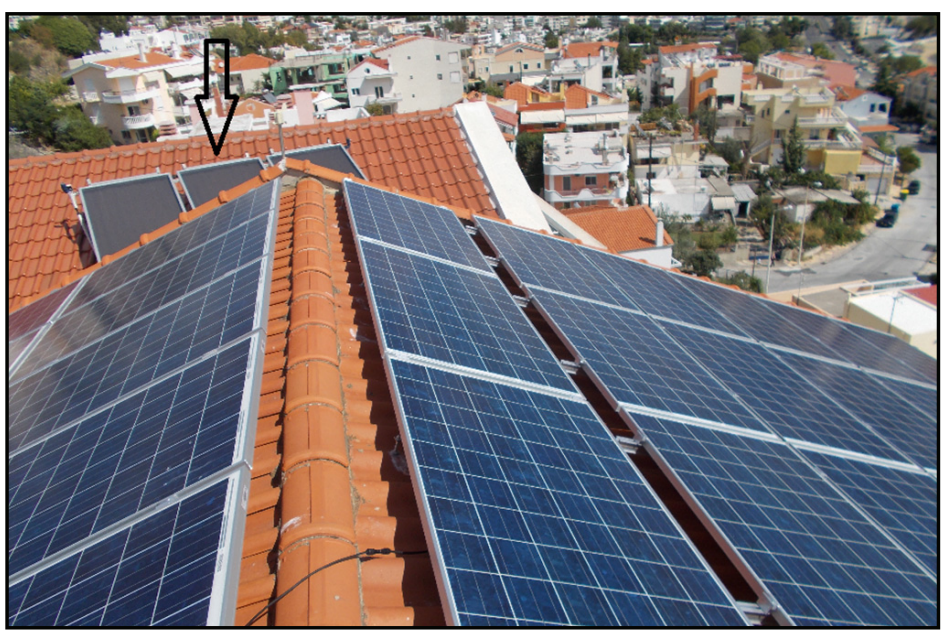

Figure 5: Panels oriented east-west direction

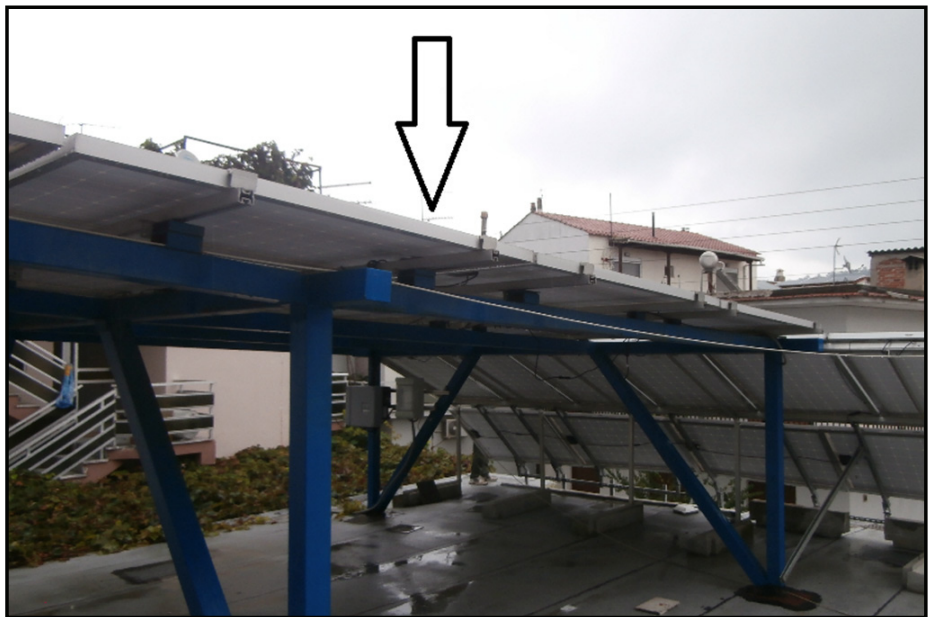

Figure 6: Horizontal positioning of roof-top PV systems

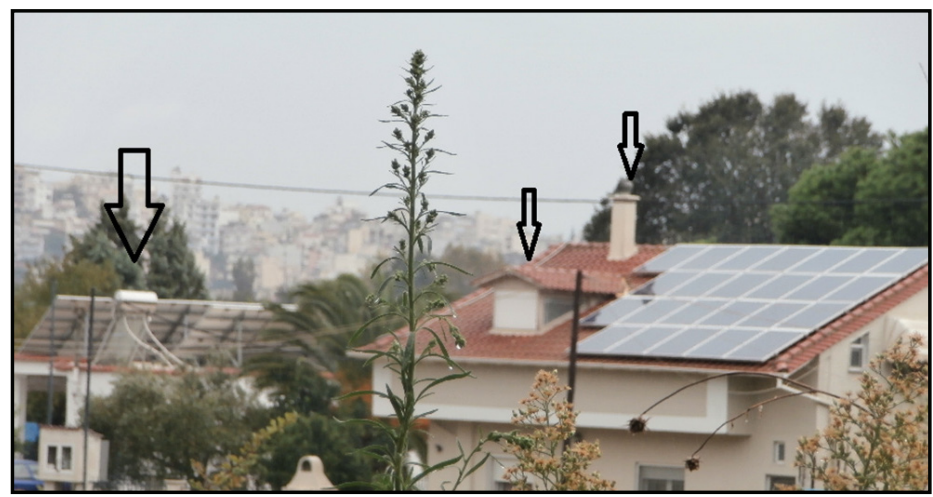

Figure 7: PV installation with shading problems 


\section{MONITORING AND SUPERVISION PROBLEMS}

A major problem in all installed PV systems we investigate, is the absence of a monitoring and supervision system, provided to confirm the proper operational state of the system. The system includes panel and string combiner sentries or devices, in bidirectional communication with a master device on the site to facilitate installation and troubleshooting of faults in the array. Timely notification of damages or dysfunctions of the PV system using a monitoring system would reduce losses in power production with the corresponding consequences. In some of these, owners realize the losses observing the statement of account at least four months later. Only the counter of HEDNO [04] is within easy reach of the clear indication of correct operation, but need constant monitoring and recording daily yield.

\section{INCORRECT SELECTION OF EQUIPMENT}

In order to propose possible improvements of the systems we identify and classifiy faults of electrical and electronic equipment. The choice of the appropriate cables to DC and AC circuits, the separation of DC strings, even the proper use of the connectors especially in DC circuits, directly affect the system performance. Also, the performance is affected by proper selection of the panel and inverter device, according to the type of installation (roof, terrace, front, etc.), the location (altitude, foggy, valley, etc.) and the nominal capacity. So we found panels exclusively for front use, mounted on the roof of a building, panels of different capacity, type and nominal voltage, connected in series. Also, inverters much higher or even much lower than the nominal total power installed. As a result, the first (max inverter) one provide reactive power to the grid, and the second (min inverter) cannot be fully effective at maximum production. Combined, the above mentioned four categories are the main causes of low efficiency of the rooftop PV systems in Kavala area, the proportion ranges from $38 \%$ to $84 \%$ of the average of power yield. Additionally when it happens that there are two or more faults on the same system then the result is catastrophic.

\section{FINAL ENERGY LOSS OF THE SYSTEMS UNDER STUDY COMPARED TO THE AVERAGE YIELD}

In accordance to the abovementioned, it is necessary to know how much energy is eventually lost because of these errors. In the Figure 8, we place the 70 worst energy performance roof-top PV systems in calendar binding sequence. The daily performance of $3,6 \mathrm{kWh} / \mathrm{kWp}$, is the average performance of the systems. This diagram shows the daily energy lost in the yellow area of the graph. According to the program the anticipated energy should have been:

$$
3,6 \times 70=252 \mathrm{kWh} / \text { day }
$$

However, real recorded yield, as shown in the graph (blue area) is:

\section{6,94 kWh/day}

While the remaining area of the graph (yellow area) is estimated by:

$$
\text { 252-196,94=55,06 kWh/day }
$$

and presents energy losses due to errors before mentioned.

\section{Elergy lost of roof-top PV systems}

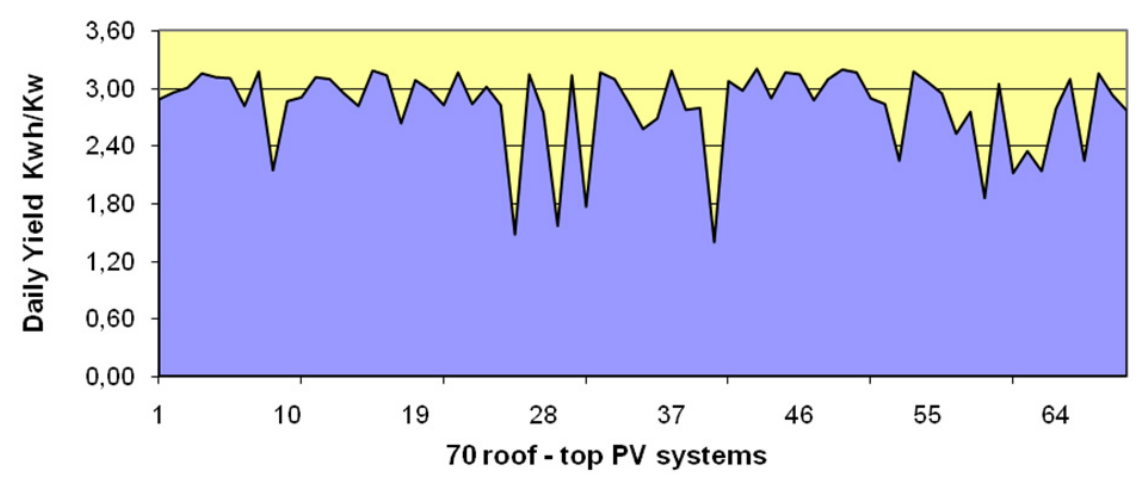

Figure 8: Lost energy from the 70 worst energy performance roof-top PV systems 


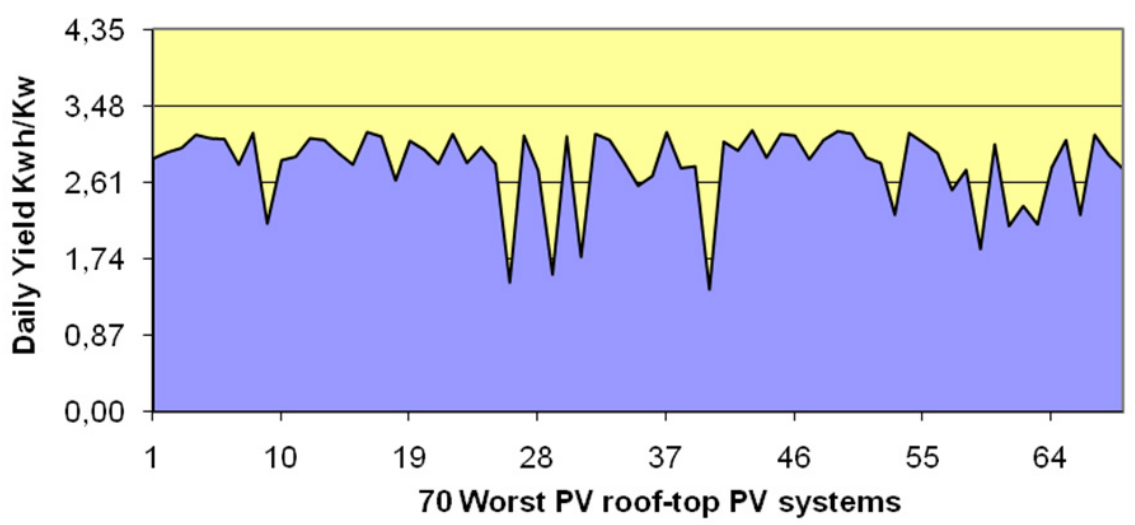

Figure 9: Lost energy from the 70 worst energy performance roof-top PV systems compared to optimal value

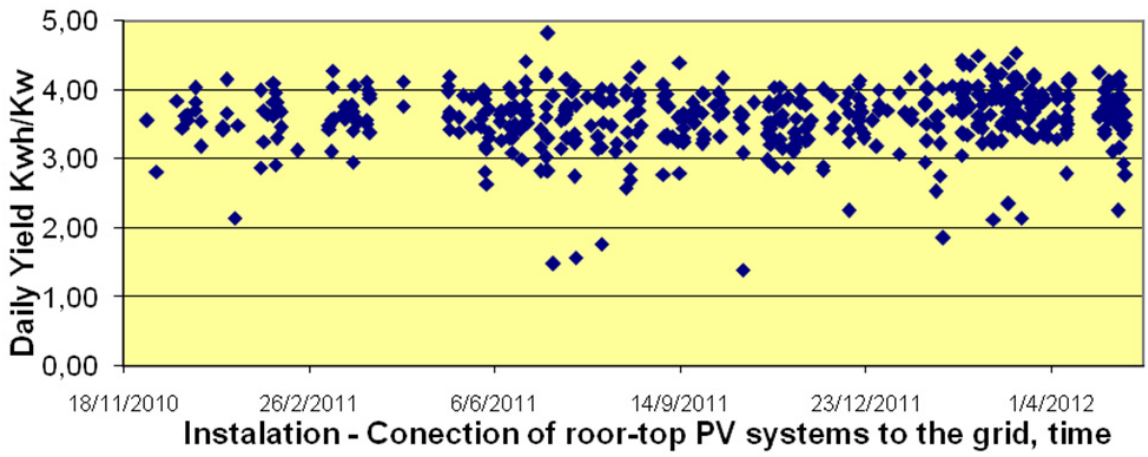

Figure 10: Characteristic curve expressing the relationship between installation time and performance of energy yield

These losses correspond to $22 \%$ of yield that could be produced if there was more appropriate planning and construction of these systems. The remaining $78 \%$ is attributed energy yield to the grid.

\section{FINAL ENERGY LOSS OF THE SYSTEMS UNDER STUDY COMPARED TO THE OPTIMAL YIELD}

The situation is even worse in the case of comparison of these systems to the optimal coefficient of performance $(4,35 \mathrm{kWh} / \mathrm{kWp})$, as shown in Figure 9. That does simply illustrate the problem at the maximum dimensions.

\section{RELATIONSHIP BETWEEN INSTALLATION TIME AND PERFORMANCE OF ENERGY YIELD}

During our investigation we observe that the first systems were connected to the grid infrequently, and as time goes, connections multiply, reaching in some cases up to five at the same day! (See Figure 10). This happen because at first, there was some hesitation from the potential investors, due to the fact that it is an innovative project, and that there was the uncertainty of the political cli- mate of Greece in this period (economic crisis). But in time, longer hesitations in the past have vanished, and various artisans, unskilled, entered the area and managed to get a significant market share. It is therefore necessary to consider whether that fact affected system performance.

\section{FINAL PERFORMANCE OF THE LISTED 512 SYSTEMS}

It is well known that the performance of PV systems is influenced by many factors. It is then recognized that the installed capacity will never be able to offer the maximum of its performance, especially in the case of installation on a roof of the building, such as the roof-top PV systems of the specific programs of the present study.

The final performance in accordance with the installed capacity is shown in the Figure 11. The vertical axis represents the installed capacity of 512 registered systems, with average $8,75 \mathrm{kWp}$, while on the horizontal axis is the daily performance of the systems.

The total installed capacity is $4.49 \mathrm{MW}$, while daily production in $1.84 \mathrm{MWh}$. According to the measurements we obtained, the total daily energy yield is: 


\section{$1782,19 \mathrm{kWh}$}

The expected energy should be according to the percentage of $78 \%$ of the energy finally attributed to the grid:

Therefore the total daily energy lost from the sum of the investigated roof-top PV systems is:

$$
1782,19 / 0,78=2284,85 \mathrm{KWh}
$$

\section{$2284,85-1782,19=502,66 \mathrm{KWh}$}

The outcome of this study is very significant, because this is the energy consumed by the district of the Old Town of Kavala, in one day! [06].

Anyway, this is the cost or loss from manufacturing defects of 512 roof-top PV systems, installed in Kavala region that presents approximately $50 \%$ of total PV roof-top systems installed.

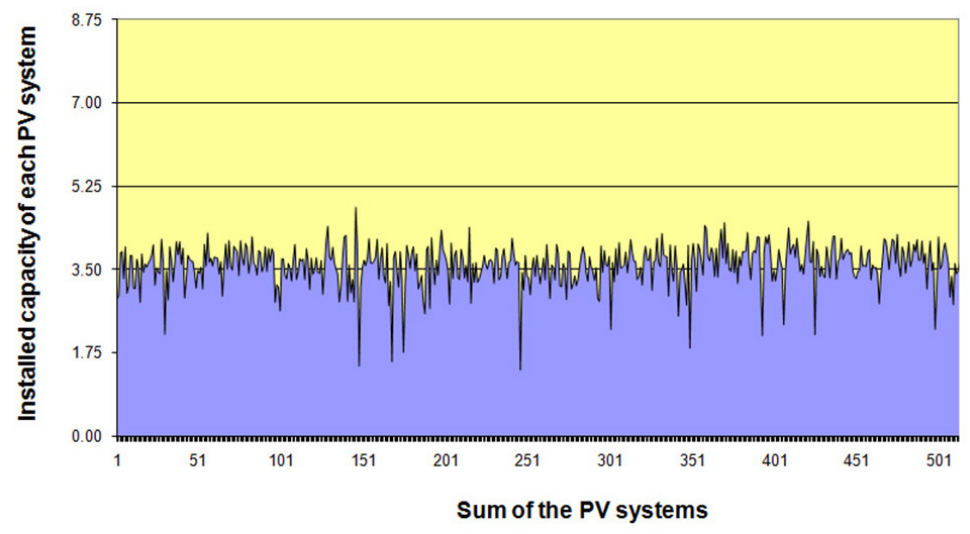

Figure 11: Final performance of the listed 512 systems compared to the installed capacity of roof-top PV systems

\section{CONCLUSION}

The outcome of this study shows that the optimization of the PV systems is strongly dependent not only on meteorological variables, such as solar energy, ambient temperature and wind speed, but also from manufacturing faults that can considerably reduce the overall performance of the systems. To study mainly the effect of these faults in the performance of systems we took precise measurements of 512 roof-top PV systems from total 990 , which is positioned in the area of prefecture of Kavala, Greece. The treatment of measurements, with a methodological framework we propose in this work, show that there is concrete quantity of energy that could be produced by the PV systems but is not, due to construction faults, (orientation, shading, monitoring, wrong equipment). The result of this study has economic and environmental impacts which are our next working topic.

\section{REFERENCES}

1) EC European Commission, 2010. Europe 2020 -A Strategy for Smart, Sustainable and Inclusive Growth. COM (2010) 2020, Brussels.

2) Elistratov, V. V., Knežević, M., Konishchev, M., \& Konishchev, M. (2014). Problems of constructing wind-diesel power plants in harsh climatic conditions. Journal of Applied Engineering Science, 12(1), 29-36.

3) Fantidis, J. G., Bandekas, D. V., Potolias, C., Vordos, N. (2013). Cost of PV electricity - Case study of Greece, Solar Energy 91, 120-130.

4) HEDNO S.A. (Hellenic Electricity Distribution Network Operator S.A.) Kavala, Greece 2014.

5) Hernández-Moro, J., Martínez-Duart J.M. (2013). Analytical model for solar PV and CSP electricity costs: Present LCOE values and their future evolution Renewable and Sustainable Energy Reviews 20, 119-132.

6) http://www.admie.gr/ retrieved on March 7th, 2015.

7) http://www.statistics.gr/ (EL.STAT.) retrieved on March $7^{\text {th }}, 2015$.

8) Joint Ministerial Decision (KYA 12323 / ГГ: 175 June 4, 2009).

9) Karatepe, E., Hiyama, T., Boztepe, M, Colak, M. (2008). Voltage based power compensation system for photovoltaic generation system under partially shaded insolation conditions. Energy Conversion and Management 49, 2307-2316.

10) Mourmouris, J.C. \& Potolias, C. (2013). A multicriteria methodology for energy planning and developing renewable energy sources at a regional level: A case study Thassos, Greece. Energy Policy 52, 522-530.

11) Poullikkas, A. (2013). A comparative assessment of net metering and feed in tariff schemes for residential PV systems. Sustainable Energy Technologies and Assessments 3, 1-8.

Paper sent to revision: 21.03.2015.

Paper ready for publication: 02.12.2015. 